\title{
Vibratory signals of four Neotropical stink bug species
}

\author{
MARIA CAROLINA BLASSIOLI MORAES ${ }^{1}$, RAUL ALBERTO \\ LAUMANN ${ }^{1}$, ANDREJ COKL ${ }^{2}$ and MIGUEL BORGES ${ }^{1}$ \\ ${ }^{1}$ Embrapa Recursos Genéticos e Biotecnologia, Brasília-DF, Brazil and ${ }^{2}$ National Institute of Biology, Ljubljana, Slovenia
}

\begin{abstract}
The stink bugs Acrosternum impicticorne, Euschistus heros, Piezodorus guildinii and Thyanta perditor (Heteroptera: Pentatomidae) feed and mate on the same host plants and constitute major components of the soybean pest complex in Brazil. During mating, they communicate with species and sex-specific vibratory signals whose spectral properties are characteristic of the subfamily Pentatominae. Songs differ between species in the time structure and amplitude modulation of their units. The repertoire of A. impicticorne, E. heros and T. perditor fits into the scheme described for most investigated stink bugs: females call with a sequence of pulses that differ between species in their duration and repetition rate, and males respond with courtship songs of species-specific temporal structure and amplitude modulation of complex pulse trains. Female calling and male courtship songs are the main constituents of vibratory communication between sexes in the mating period. The other vibratory emissions appear to represent either transitional songs, support recognition during close-range courtship, or are involved in male rivalry. The first recorded vibratory emissions of $P$. guildinii confirm that the genus Piezodorus represents an exception within the Pentatominae. Irregularly repeated female vibratory signals of $P$. guildinii do not trigger typical male courtship responses as they would in the small stink bugs Holcostethus strictus and Murgantia histrionica. On the other hand, complex rivalry with extensive frequency modulation of pulses, as also described in Piezodorus lituratus, opens a new insight into the role of vibratory communication in stink bugs.
\end{abstract}

Key words. Brazil, mating behaviour, soybean pest complex, stink bugs, substrate-borne vibrational signals.

\section{Introduction}

Pentatomidae, with its 4123 described species, is one of the largest families within the Heteroptera, and plant-feeding stink bugs (Pentatominae) comprise its largest subfamily with several economically important pest species (Panizzi et al., 2000). Vibratory signals have been recorded, analysed and correlated with mating behaviour in Nezara viridula (Čokl et al., 2000a, b), Nezara antennata (Kon et al., 1988), Palomena prasina and Palomena viridissima (Čokl et al., 1978), Piezodorus lituratus (Gogala \& Razpotnik, 1974),

\footnotetext{
Correspondence: Dr Maria Carolina Blassioli Moraes, Embrapa Recursos Genéticos e Biotecnologia, Caixa Postal 02372, 70849970 Brazilia-DF, Brazil. Tel.: +55 61 4484683; fax: +55 61 4484673; e-mail: mcbmorae@cenargen.embrapa.br
}

Acrosternum hilare (Čokl etal., 2001), Thyanta custator accerra and Thyanta pallidovirens (McBrien etal., 2002), Holcostethus strictus (Pavlovčič \& Čokl, 2001), Euschistus conspersus (McBrien \& Millar, 2003) and Murgantia histrionica (Čokl etal., 2004). Although the exchange of species- and sex-specific vibratory signals plays a key role before copulation, data indicate that species recognition based on different temporal patterns of vibratory songs does not completely prevent intra- and interspecific hybridization. For example, interspecific copulations have been observed in the field between $N$. antennata and N. viridula (Kiritani etal., 1963) and species-specific temporal characteristics do not prevent cross mating between different southern green stink bug populations (Čokl et al., 2000b). In this respect, male-emitted pheromones may provide an additional barrier to hybridization, and recent data confirm that species-specific 
chemical (McBrien \& Millar, 1999) and vibratory signals (Čokl \& Virant-Doberlet, 2003) interact during communication in the premating period (Miklas etal., 2003).

Although basic steps in the mating behaviour of stink bugs have been described (Borges et al., 1987) and later confirmed in several species (Čokl \& Virant-Doberlet, 2003), there are still several open questions. There is no information about the modality of signals that trigger female calling in the first steps of substrate-borne vibrational communication on a plant. In small pentatomid species, such as $H$. strictus and $M$. histrionica, the calling phase is lacking or less expressed by females and they are not always first to start vibrational communication (Pavlovčič \& Čokl, 2001; Čokl etal., 2004). Furthermore, no female songs have been recorded in $P$. lituratus (Gogala \& Razpotnik, 1974) and the first emitted male song has, in many species, a less stable temporal structure, indicating that it may represent a transitional form either to male courtship or rivalry song.

For a better understanding of the pentatomid language expressed by vibratory signals transmitted through plants, songs have to be recorded and analysed from many different species from different continents. Compared with North America or Europe, there are few data on vibrational songs of species living in South America (Č okl et al., 2000b). Thus, the vibratory song repertoire of the four stink bug species living in Brazil that constitute the major components of the soybean pest complex is investigated in the present study. The vibratory songs of Acrosternum impicticorne (Stål), Euschistus heros (F.), Piezedorus guildinii (Westwood) and Thyanta perditor (F.) are recorded, analysed to determine the level of species specificity of their spectral and temporal properties, and compared with songs of other previously investigated stink bugs. The aim of the study is to determine general characteristics of Pentatominae language as expressed by vibratory signals and, in particular, to illuminate differences between these four sympatric species, which feed and mate on the same host plants in Brazil.

\section{Materials and methods}

Insects

All experiments were conducted on adult stink bugs of the species A. impicticorne, E. heros, $P$. guildinii and $T$. perditor from laboratory colonies started from adults and nymphs collected on soybean fields near Brazilia, DF, Brazil $\left(15^{\circ} 47^{\prime} \mathrm{S}\right.$ and $\left.47^{\circ} 55^{\prime} \mathrm{W}\right)$. Males and females, separated 2 days after the final moult, were reared in plastic cages (height $26 \mathrm{~cm}$, diameter $22 \mathrm{~cm}$ ) at Embrapa Research Institute in Brazilia in an environmental room at $26.0 \pm 1.0^{\circ} \mathrm{C}$ and $60 \pm 10 \% \mathrm{RH}$, under an LD $14: 10 \mathrm{~h}$ photoperiod with lighting provided by 16 fluorescent lights of $40 \mathrm{~W}$. Insects were reared on sunflower seeds (Helianthus annuus L.), soybean (Glycine $\max$ L.), raw peanut seeds (Arachis hypogaea L.) and green beans (Phaseolus vulgaris L.). Food was changed three times per week.

\section{Recording and analysing vibratory songs}

Vibratory signals were recorded from virgin and sexually mature bugs (15-25 days after the final moult) (Brennan et al., 1977; Costa et al., 1998) between 08.00 and $21.00 \mathrm{~h}$ in a sound insulated cage $(80 \times 80 \times 80 \mathrm{~cm})$ under daylight conditions, room temperature $\left(26.0 \pm 1.0^{\circ} \mathrm{C}\right)$ and humidity $(65 \pm 10 \%)$. To begin the experiment, a male and a female were placed on the membrane of a loudspeaker $(10 \mathrm{~cm}$ in diameter low-midrange loudspeaker, $40-6000 \mathrm{~Hz}$ frequency response, impedance $8 \mathrm{O}$, Radioshack, Taiwan). A 2-cm high, vaseline-coated translucent plastic cylinder was placed over the speaker without contacting the loudspeaker membrane to prevent the insect moving away from the membrane surface. The loudspeaker was positioned on a vibration-free base within a sound insulated cage to avoid environmental noise. Vibrations recorded by the loudspeaker were amplified by a microphone amplifier (Sonifex Redbox, Type RB-MA1; http://www.sonifex.co.uk/redbox/ index.shtml) and home-made operational amplifier TL081CN; http://www.mouser.com), digitized (AardvarkDirect Pro 24/96; Aardvark Computer Systems, Washington, District of Columbia) and stored on a computer by the use of Cool EditPro software (Syntrillium Software 2001; Fort Wayne, Indiana).

Vibrations emitted by the insect pair were followed in real time with headphones and recorded until they stopped singing for more than $5 \mathrm{~min}$. To determine the male or female origin of emitted signals, one bug of a dueting couple was removed and, to evoke rivalry singing, two males were combined with one female. Behaviour during singing on a loudspeaker was visually monitored by an observer and each individual bug was tested only once per day.

Vibratory signals were analysed using Sound Forge 4.5 software (Sonic Foundry; http://www.sonicfoundry.com). A pulse was defined as a unitary homogeneous parcel of vibration of finite duration (Broughton, 1963), pulse trains as repeatable and temporally distinct groups of pulses and a song as a sequence of pulses and/or pulse trains with a distinct beginning and end. Spectra were characterized by the dominant, first harmonic and other subdominant frequency peaks, by the spectral width $20 \mathrm{~dB}$ below the dominant frequency value and by frequency modulation described as downward- or upward-orientated frequency sweepquantified by the frequency difference per signal duration $\left(\mathrm{Hz} \mathrm{s}^{-1}\right)$. Temporal characteristics of pulses and/or pulse trains were presented as pulse/or pulse train duration and repetition time (the time difference between onsets of two consecutive pulses or pulse trains). Songs were classified, according to their order of appearance in a dueting couple (Čokl et al., 2001), as female songs 1 and 2 (FS-1 and FS-2), male songs 1, 2 and 3 (MS-1, MS-2 and MS-3) or male rivalry song (MRS).

Data are presented as means $\pm \mathrm{SD}$, together with the number of signals analysed $(N)$ and the numbers of individuals $(n)$ from which signals were averaged. Signals were used only from those bugs for which inter-individual differences did not vary significantly (analysis of variance, single 
factor or Kruskal-Wallis for data not normally distributed). Differences between means were determined with Student's $t$-tests or the Mann-Whitney $U$-test when data were not normally distributed.

\section{Results}

\section{Vibrational signals of $A$. impicticorne}

To describe the song repertoire of $A$. impicticorne, vibrational signals were analysed from 27 males and 16 females tested in 43 couples. In 20 of them, songs were emitted by both sexes, and only males sang in 17 pairs (15 emitting MS-1 and two emitting MS-2) and only females sang in six pairs (three females emitting FS-1 and 3 FS-2). In all singing couples, females started vibrational communication. In the time between 08.00 and $13.00 \mathrm{~h}$, songs were recorded in $54 \%$ $(n=24)$ of tested couples and, in the afternoon (from $13.00-19.00 \mathrm{~h})$, in $90 \%(n=40)$ of tested couples. Mating behaviour with substrate-borne sound communication ended with copulation in two couples in the morning and in 10 couples in the afternoon. A MRS was recorded in a single combination of two males with a female.

Vibratory communication of a couple started with a female singing, FS-1 (Fig. 1A,B, Table 1), the temporal and spectral characteristics of which varied depending upon whether or not the male responded. FS-1 pulse trains, composed of a long and a short pulse, were repeated significantly faster $(t$-test, $P<0.001)$ when emitted in the absence of male response. The dominant frequency of short pulses was significantly lower than that of long pulses (Mann-Whitney test, $P<0.001$ ). The dominant frequency of pulse trains was significantly higher when a female was singing in the absence of male response (Mann-Whitney test, $P<0.001)$. This phenomenon may be explained by a higher proportion of long pulses whose dominant frequencies were significantly higher than those of short pulses (Mann-Whitney test, $P<0.001$ ). A narrow dominant frequency peak spectrum of FS-1 was characterized by a mean width of $10 \pm 3 \mathrm{~Hz}(N=90, n=4)$ at $20 \mathrm{~dB}$ below peak amplitude; FS-1 has a well defined dominant spectral peak with higher harmonics.

Females emitted FS-2, in the presence or absence of males, as a sequence of pulse trains. Two typical pulse trains were characterized as a short pulse train and another as a long pulse train (Fig. 2A,B, Table 2). The short pulse train is formed by $5 \pm 2$ pulses with mean duration of $1129 \pm 190 \mathrm{~ms}(N=22, n=4)$ and the long pulse train is formed of $12 \pm 3$ pulses with mean duration of $1802 \pm 454 \mathrm{~ms} \quad(N=69, n=4)$. No correlation between pulse train duration and the level of male responding was observed.

As recorded for FS-1, the repetition time of pulse trains in FS-2 was longer when both genders were singing (MannWhitney test, $P<0.05$ ) and the dominant frequency of pulse trains and pulses were significantly higher when emitted in the absence of a male responding (Mann-Whitney test, $P<0.001$ ) (Table 2). The FS-2 was composed of pulse trains with broad-band frequency characteristics [width $75 \pm 12 \mathrm{~Hz}(N=70, n=4)$ at $20 \mathrm{~dB}$ below peak amplitude].

The MS-1 pulse trains (Fig. 3A) were emitted in the absence of a female. However, the MS-1 was recorded also in the presence of female, triggered by FS-1 or FS-2. Pulse train duration depended on the number of pulses within a group (Table 3). Two main groups were recorded, one with $6 \pm 1$ pulses/train $(N=79, n=4)$ and the other with $12 \pm 3$ pulses/train $(N=45, n=5)$. No correlation was found between pulse train duration in the MS- 1 and the presence or absence of female singing. On the other hand, the MS-1 repetition time was shorter when the song was emitted without female singing (Table 3). By contrast to FS-1, no difference was found in the dominant frequency of MS-1 pulse trains emitted in the presence or absence of female singing (Mann-Whitney test, $P=0.48$ ). The first male-emitted song, MS-1, was composed of pulse trains with narrowerband frequency characteristics [width $23 \pm 6 \mathrm{~Hz}(N=128$, $n=3$ ) at $20 \mathrm{~dB}$ below peak amplitude] and without an apparent first harmonic or any other subdominant peaks (Fig. 3B). The dominant frequency of single pulses in the MS-1 varied within the group. For example, the two first and last pulses had significantly lower dominant frequency $(94 \pm 6 \mathrm{~Hz}, N=57, n=3)$ than the middle ones $(120 \pm 4 \mathrm{~Hz}$, $N=67, n=3$ ) (Mann-Whitney test, $P<0.05$ ) (Fig. 3A).

The MS-2 (Fig. 4A,B, Table 4) had a similar temporal structure to MS-1 but was always emitted as a response to FS-1 or FS-2. Before copulation, the female stopped singing and the male emitted just single pulses, which were not grouped into distinct pulse trains. The pulse train duration was similar to MS-1 and varied according to the number of pulses per pulse train; for example, two main groups with $6 \pm 1(N=114, n=5)$ or $10 \pm 4(N=86, n=7)$ pulses could be distinguished. The MS-2, similar to MS-1, was also composed of pulse trains with narrower-band frequency characteristics [width $13 \pm 8 \mathrm{~Hz}(N=100, n=3)$ at $20 \mathrm{~dB}$ below peak amplitude] but it was composed by a clear first harmonic peak (Fig. 4B). There was no frequency modulation within single pulses. The occurrence of pulses of different duration within the MS-2 pulse trains was seldom recorded.

The MRS was characterized by regularly repeated pulses exchanged between two males in an $\mathrm{a}-\mathrm{b}-\mathrm{a}-\mathrm{b}-\mathrm{a}-\mathrm{b}$... fashion (Fig. 5A,B, Table 5). The spectra showed very broadband peaks (spectral width $79.9 \pm 11.3 \mathrm{~Hz}, N=60, n=3$ at $20 \mathrm{~dB}$ below peak amplitude) without any distinct frequency modulation and a no clearly defined dominant spectral peak or harmonics (Fig. 5B).

\section{Vibrational signals of E. heros}

To describe the song repertoire of the E. heros vibrationary signals emitted by 29 males and 27 females (27 pairs) were analysed. In 10 couples, successful copulation followed male and female singing. Two female (FS-1, FS-2) and four 
A

Acrosternum impicticorne

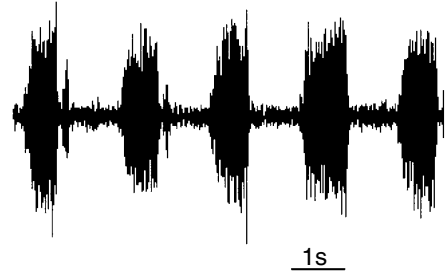

C

Euschistus heros

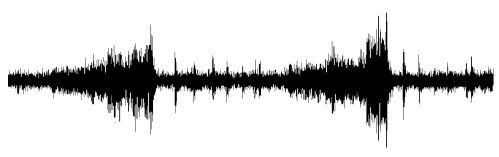

1s

E

Piezodorus guildinii

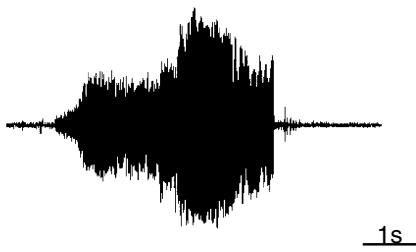

G

Thyanta perditor

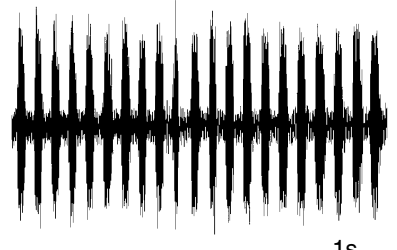

B
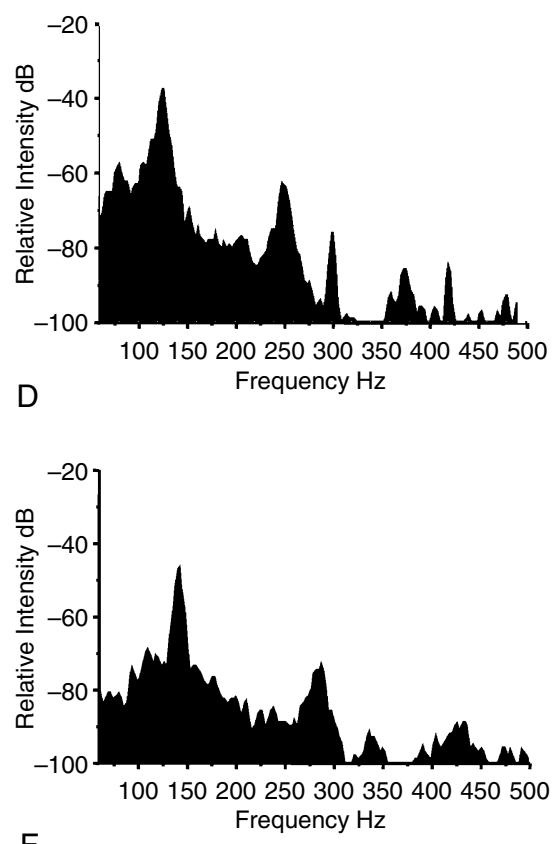

$\mathrm{F}$

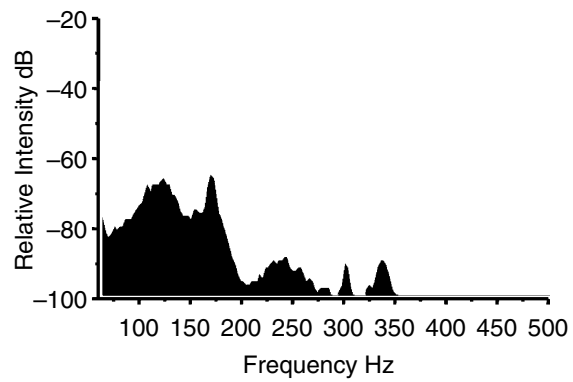

$\mathrm{H}$

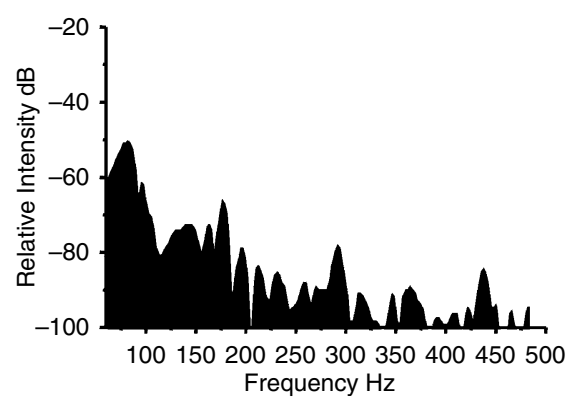

Fig.1. (A) Oscillogram of Acrosternum impicticorne female song 1 (FS-1) and (B) frequency spectrum of one pulse. (C) Oscillogram of Euschistus heros female song 1 (FS-1) and (D) frequency spectrum of one pulse. (E) Oscillogram of Piezodorus guildinii female song 1 (FS-1) and (F) frequency spectrum of one pulse. (G) Oscillogram of Thyanta perditor female song 1 (FS-1) and (H) frequency spectrum of one pulse. Songs were registered from bugs singing on a loudspeaker membrane. The time scales are marked below each oscillogram. male (MS-1, MS-2, MS-3 and MRS) songs were identified as differing in their temporal and spectral characteristics.

Temporal characteristics of the FS-1 (Fig. 1C,D, Table 1) resemble those of a typical pentatomid female calling song (Čokl et al., 2001, McBrien \& Millar, 1999). The song was emitted as the first in a female/male duet, had an autonomous repetition rate of pulses with small amplitude modulation, and triggered the emission of MS-1 and MS-2, respectively. Spectra were characterized by narrow dominant and first harmonic peaks and by a rising frequency sweep $\left(14.2 \pm 4.9 \mathrm{~Hz} \mathrm{~s}^{-1}, N=36, n=4\right)$ over the course of each pulse. The FS-2 (Fig. 2C,D, Table 2) consisted of irregularly repeated and several seconds long pulses with extensive amplitude modulation. Compared with FS-1, the FS-2 spectra were characterized by downward-orientated frequency sweeps over the course of each pulse $\left(4.1 \pm 1.7 \mathrm{~Hz} \mathrm{~s}^{-1}, N=44, n=5\right.$ for the dominant frequency and $7.4 \pm 2.7 \mathrm{~Hz} \mathrm{~s}^{-1}, N=44, n=5$ for the first harmonic frequency) and by broader dominant and first harmonic spectral peaks. 
Table 1. Temporal and spectral characteristics of female song 1 (FS-1) of Acrosternum impicticorne, Euschistus heros, Piezodorus guildinii and Thyanta perditor.

\begin{tabular}{|c|c|c|c|c|c|}
\hline Species & & $\begin{array}{l}\text { Duration (ms) } \\
(N / n)\end{array}$ & $\begin{array}{l}\text { Repetition time (ms) } \\
(N / n)\end{array}$ & $\begin{array}{l}\mathrm{P} / \mathrm{PT} \\
(N / n)\end{array}$ & $\begin{array}{l}\text { Dominant frequency }(\mathrm{Hz}) \\
(N / n)\end{array}$ \\
\hline \multirow[t]{4}{*}{ Acrosternum impicticorne } & PT & $811 \pm 34(150 / 6)$ & $1731 \pm 54(112 / 3)^{*}$ & $2 \pm 1(98 / 3)$ & $133 \pm 4(180 / 4)^{*}$ \\
\hline & & & $2024 \pm 43(48 / 2)^{* *}$ & $4 \pm 1(25 / 2)$ & $105 \pm 8(110 / 2)^{* *}$ \\
\hline & $\mathrm{P}$ & $560 \pm 50(159 / 6)^{\mathrm{L}}$ & $960 \pm 79(89 / 4)$ & NA & $125 \pm 2(90 / 4)^{\mathrm{L}}$ \\
\hline & & $112 \pm 11(159 / 6)^{\mathrm{S}}$ & & & $100 \pm 5(78 / 4)^{\mathrm{S}}$ \\
\hline Euschistus heros & $\mathrm{P}$ & $948 \pm 183(79 / 5)$ & $3566 \pm 1043(74 / 5)$ & NA & $145 \pm 7(77 / 5)$ \\
\hline \multirow[t]{2}{*}{ Piezodorus guildinii } & $P$ & $4908 \pm 641(70 / 3)$ & NA & NA & $168 \pm 10(35 / 3)^{\mathrm{a}}$ \\
\hline & & & & & $120 \pm 6(35 / 3)^{\mathrm{b}}$ \\
\hline \multirow[t]{2}{*}{ Thyanta perditor } & PT & $13410 \pm 1944(52 / 7)$ & $18810 \pm 2343(52 / 7)$ & $34 \pm 21(52 / 7)$ & ND \\
\hline & $\mathrm{P}$ & $210 \pm 40(117 / 7)$ & $370 \pm 50(100 / 6)$ & NA & $79 \pm 6(117 / 7)$ \\
\hline
\end{tabular}

Means \pm SD are shown together with the number of tested signals $(N)$ and the number of tested females $(n), N / n$. P-pulses, PT-pulse trains. NA, Not applicable; ND, not determined.

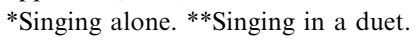

${ }^{\mathrm{L}}$ Long pulse.

Short pulse.

${ }^{\text {a }}$ First part of the pulse.

${ }^{\mathrm{b}}$ Second part of the pulse.

The MS-1 (Fig. 3C,D, Table 3) was triggered by female singing and its pulse trains were produced in response to FS-1 pulses. Single pulses as a transitional response to FS-1 are the origin of MS-1 pulse trains, and their repetition rate increases up to their fusion into a fully developed MS-1 pulse train, culminating in a well established male-female alternation. Spectral peaks of MS-1 pulse trains are broader than those of FS-1 and FS-2. Two peaks within the dominant frequency domain could be shown (Fig. 3D). Throughout the pulse train, a $5.6 \pm 3.9 \mathrm{~Hz} \mathrm{~s}^{-1}$ sweep from higher to lower frequency values could be recorded. In pauses between MS-1/FS-1 alternations, males emitted significantly longer $(P<0.001)$ pulse trains of similar amplitude modulation and similar spectral characteristics. Single pulse trains, as characterized for the MS-2, are not triggered by FS-1 or FS-2 although they appeared in several cases in connection with FS-2 or as precursors to FS-1/MS-1 alternation (Fig. 4C,D, Table 4). Two spectral peaks within the dominant frequency domain and a less expressed downward-orientated frequency sweep $\left(5.2 \pm 1.9 \mathrm{~Hz} \mathrm{~s}^{-1}\right.$ for the dominant frequency and $7.9 \pm 2.6 \mathrm{~Hz} \mathrm{~s}^{-1}$ for the first harmonic frequency, $N=47, n=8$ ) throughout the whole MS-2 pulse train duration characterize MS-2 spectral properties. The number of pulses in pulse train of MS-1 and MS-2 was not determined because they were fused with the female FS- 1 and FS-2 (Tables 3 and 4).

The MRS was emitted only once in a combination of two males and one female (Fig. 5C,D, Table 5). Apparently, and by contrast to MRS as described in the Nezara viridula bug (Čokl \& Virant-Doberlet, 2003) and that observed in this work for A. impicticorne and T. perditor, singing rivalry did not alternate in an $\mathrm{a}-\mathrm{b}-\mathrm{a}-\mathrm{b}-\mathrm{a} \ldots$ fashion. During recordings with two males, when one male was singing MRS, the other remained silent for a few seconds and then emitted a MS- 1 signal in an $\mathrm{a}-\mathrm{a}-\mathrm{a}-\mathrm{b}-\mathrm{a}-\mathrm{a}-\mathrm{a}-\mathrm{b} \ldots$ fashion. The MRS consisted of a sequence of frequency modulated pulses the spectra of which showed two peaks in the first harmonic frequency domain, the lower one at $251 \pm 10 \mathrm{~Hz}(N=28$, $n=1)$ and the higher one at $300 \pm 6 \mathrm{~Hz}(N=28, n=1)$. In the first half of the MRS pulse, the frequency sweep of $71 \pm 38 \mathrm{~Hz} \mathrm{~s}^{-1}(N=21, n=1)$ was orientated downward from $165 \pm 3 \mathrm{~Hz}(N=21, n=1)$ to $141 \pm 11 \mathrm{~Hz}(N=21$, $n=1)$ and, in the rest, the frequency increased from $141 \pm 11 \mathrm{~Hz}(N=21, n=1)$ to $155 \pm 6 \mathrm{~Hz}(N=21, n=1)$ $\left(31 \pm 27 \mathrm{~Hz} \mathrm{~s}^{-1}\right)$.

During head-butting or when following the unreceptive female (Borges et al., 1987), the male emitted a song (MS-3) that consisted of irregularly repeated pulse trains (Fig. 6A,B, Table 6). The emission of MS-3 was recorded together with FS-1 and spectra were characterized by a broad dominant frequency peak without a prominent first harmonic or frequency modulation (Fig. 6B).

\section{Vibrational signals of $P$. guildinii}

Thirty-nine males and 36 females were paired and songs were recorded in 18 of 36 couples; both sexes sang in 14 pairs and in four pairs only females emitted vibratory signals. Copulation was observed in two pairs. Females emitted two songs of which FS-1 (Fig. 1E,F, Table 1) was recorded in the presence of the male and characterized as a long single pulse. The FS-2 (Fig. 2E,F, Table 2) was recorded only when a female was alone or together with another female on a loudspeaker membrane. The long single pulse (FS-1) that was repeated unevenly is typically composed of two parts. Duration time and dominant frequency of the first part $(2740 \pm 320 \mathrm{~ms}, N=35, n=3$ and $168 \pm 10, N=35, n=3$ ) are significantly different (MannWhitney test, $P<0.05$ ) when compared with the second 
A
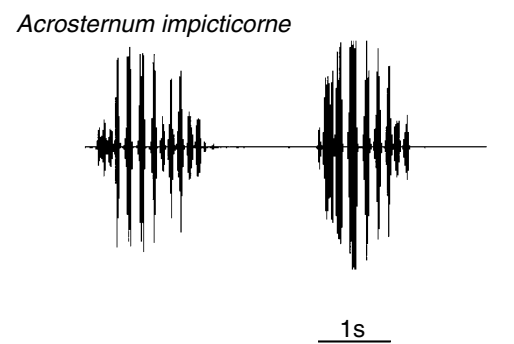

C

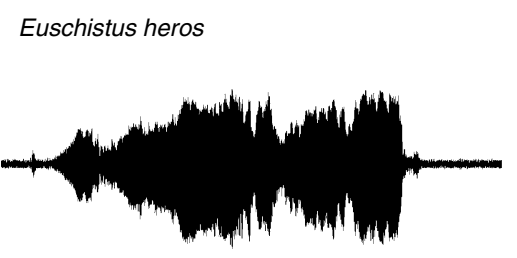

1s

\section{E}

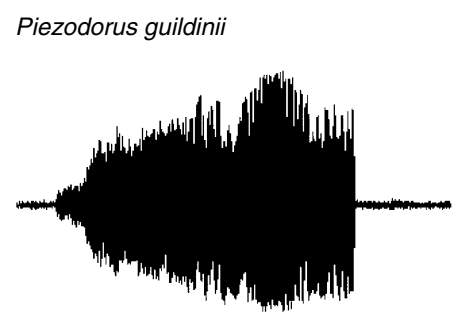

$1 \mathrm{~s}$

G

Thyanta perditor

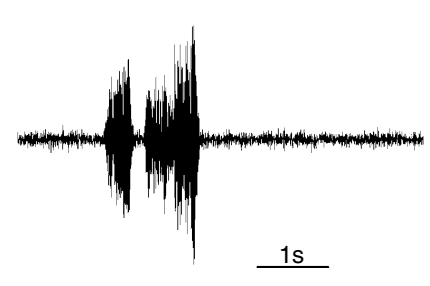

B

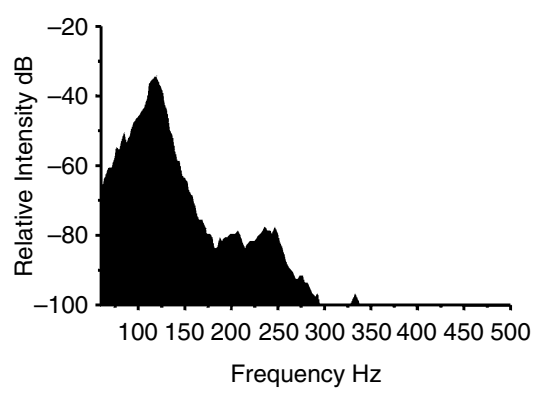

D

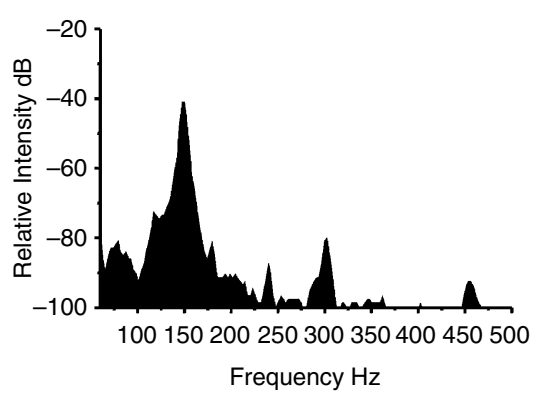

$\mathrm{F}$

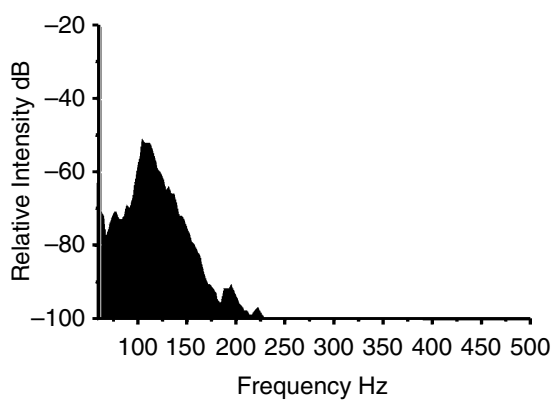

$\mathrm{H}$

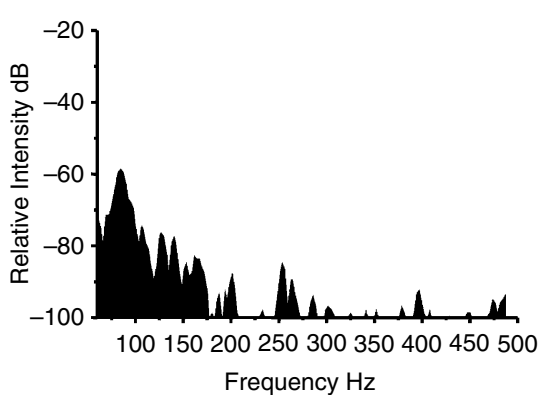

Fig. 2. (A) Oscillogram of Acrosternum impicticorne female song 2 (FS-2) and (B) frequency spectrum of one pulse. (C) Oscillogram of Euschistus heros female song 2 (FS-2) and (D) frequency spectrum of one pulse. (E) Oscillogram of Piezodorus guildinii female song 2 (FS-2) and (F) frequency spectrum of one pulse. (G) Oscillogram of Thyanta perditor female song 2 (FS-2) and (H) frequency spectrum of one pulse. Songs were registered from bugs singing on a loudspeaker membrane. The time scales are marked below each oscillogram. part $(1800 \pm 200 \mathrm{~ms}, N=35, n=3$ and $120 \pm 6 \mathrm{~Hz}, N=35$, $n=3)$ of the pulse. The FS-1 showed very broad-band frequency characteristics (Fig. 1F) $(169 \pm 21 \mathrm{~Hz}, N=35$, $n=3$ ) and did not show a well-defined dominant spectral peak or any harmonic peak.

The FS-2 pulses resemble those of the FS-1, although their duration and dominant frequency differed signifi- cantly $(P<0.05$, Mann-Whitney test). In addition, FS-2 had a medium-band frequency attribute (Fig. 2F) $(58 \pm 11 \mathrm{~Hz}, N=25, n=3)$ with a well-expressed dominant spectral peak without any harmonics.

Males never sang when placed alone on a loudspeaker but emitted the MS-1 (Fig. 3E,F, Table 3) after approaching and antennating a female. The MS-1 song was composed of 
Table 2. Temporal and spectral characteristics of female song 2 (FS-2) of Acrosternum impicticorne, Euschistus heros, Piezodorus guildinii and Thyanta perditor.

\begin{tabular}{llcccc}
\hline Species & & $\begin{array}{l}\text { Duration }(\mathrm{ms})(N / n) \\
(N / n)\end{array}$ & $\begin{array}{l}\text { Repetition time }(\mathrm{ms})(N / n) \\
(N / n)\end{array}$ & $\begin{array}{l}\text { P/PT }(N / n) \\
(N / n)\end{array}$ & $\begin{array}{l}\text { Dominant frequency }(\mathrm{Hz}) \\
(N / n)\end{array}$ \\
\hline Acrosternum impicticorne & $\mathrm{PT}$ & $1129 \pm 190(22 / 4)^{\mathrm{S}}$ & $5335 \pm 326(66 / 4)^{* *}$ & $5 \pm 2(22 / 4)^{\mathrm{S}}$ & $\begin{array}{l}109 \pm 6\left(178 / 3123 \pm 7(58 / 2)^{*}\right. \\
123 \pm 7(58 / 2)^{*} \\
\end{array}$ \\
& $\mathrm{P}$ & $1802 \pm 454(69 / 4)^{\mathrm{L}}$ & $2849 \pm 735(56 / 3)^{*}$ & $12 \pm 3(69 / 4)^{\mathrm{L}}$ & $106 \pm 6(70 / 3)^{* *}$ \\
& & $113 \pm 29(334 / 5)$ & $180 \pm 39(236 / 4)$ & NA & $131 \pm 6(114 / 3)^{*}$ \\
Euschistus heros & $\mathrm{PT}$ & $5663 \pm 1198(44 / 6)$ & NA & ND & $157 \pm 7(44 / 6)$ \\
Piezodorus guildinii & $\mathrm{P}$ & $4630 \pm 200(41 / 3)$ & $18630 \pm 1780(41 / 3)$ & $\mathrm{NA}$ & $83 \pm 4(81 / 4)^{\mathrm{S}}$ \\
Thyanta perditor & $\mathrm{P}$ & $710 \pm 290(73 / 4)^{\mathrm{S}}$ & $1897 \pm 1102(44 / 4)^{\mathrm{S}}$ & $\mathrm{NA}$ & $84 \pm 4(14 / 4)^{\mathrm{L}}$ \\
\hline
\end{tabular}

Means $\pm \mathrm{SD}$ are shown together with the number of tested signals $(N)$ and the number of tested females $(n), N / n$. P-pulses, PT-pulse trains. NA, Not applicable; ND, not determined.

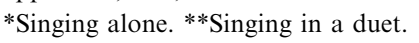

${ }^{\mathrm{L}}$ Long pulse train or pulse.

${ }^{\mathrm{s}}$ Short pulse train or pulse.

sequences of short pulses in which the spectra showed a broad dominant frequency peak $(71 \pm 20 \mathrm{~Hz}, \quad N=44$, $n=2$ ) and neither harmonics nor frequency modulation were recorded. The MRS (Fig. 5E,F, Table 5) showed a narrow-band peak $(25 \pm 7 \mathrm{~Hz}, N=24, n=3)$ and was recorded only in the presence of another male, and carried all the characteristics of a rivalry song as described previously.

\section{Vibrational signals of $T$. perditor}

Songs of $T$. perditor were recorded in 52 of 82 pairs. Songs were emitted more frequently in the afternoon $(15.00-19.00 \mathrm{~h}$, songs recorded in $76 \%$ of the pairs, $N=67)$ than in the morning $(08.00-13.00 \mathrm{~h}$, one out of 15 pairs).

Nineteen pairs copulated in the afternoon and none in the morning. Signals emitted by 11 females and 31 males were analysed. Two female (FS-1 and FS-2) and four male songs (MS-1, MS-2, MS-3 and MRS) could be differentiated in the repertoire of this species.

The FS-1 (Fig. 1G,H, Table 1) carried characteristics of a typical pentatomid female calling song (Čokl \& VirantDoberlet, 2003). The song appeared first as a duet. Pulse trains were repeated with a steady rate autonomously for a period of several minutes without the male responding or even being present. The FS-2 (Fig. 2G,H, Table 2) was characterized by sequences of pulses, the duration and repetition rate of which differed significantly (Mann-Whitney test, $P<0.001$ and $P<0.01$, respectively). Long FS-2 pulses were observed only when females were singing in the absence of a male and short when they were singing both alone or with males. Duration and repetition time of FS-2 did not depend on the presence or the absence of a male (Mann-Whitney test, $P=0.50$ and $P=0.60$, for duration and repetition time, respectively). No difference was found in spectral properties of short FS-2 pulses emitted in the presence or absence of a male (Mann-Whitney test, $P=0.16)$. The FS-2 spectra with $20 \mathrm{~dB}$ below peak amplitude $(17 \pm 6 \mathrm{~Hz}, N=12, n=4)$ was significantly $(P<0.001)$ narrower than FS-1 $(46 \pm 7 \mathrm{~Hz}, N=20, n=7)$.

The MS-1 (Fig. 3G,H, Table 3) was emitted in the presence or absence of a female and was composed of several second pulse trains. Pulse duration was not significantly different when emitted with or without female responses (Mann-Whitney test, $P=0.35$ ). On the other hand, pulses emitted in a duet were repeated significantly faster and had lower dominant frequency (Mann-Whitney test, $P<0.05$ for both).

The MS-2 (Fig. 4D,E, Table 4) had its origin in MS-1, which preceded MS-2 pulses and sometimes followed its emission. The song usually appeared in response to female singing and, in this case, pulse duration was significantly longer than that emitted in the absence of female ( $t$-test, $P<0.01)$. By contrast to MS-1, the dominant frequency did not differ when emitted in the presence or absence of female (Mann-Whitney test, $P=0.89$ ) and spectral width was narrower $(7 \pm 2 \mathrm{~Hz}, N=20, n=8)$ than in $\mathrm{MS}-1(36 \mathrm{~Hz} \pm 9$, $N=20, n=7)$.

During head-butting and antennation of a female, males emitted a song (MS-3) (Fig. 6C,D, Table 6) that preceded copulation and silenced the singing female. Pulses were fused into a pulse train and, despite inter-individual differences, the song could be attributed mainly to getting the female ready for copulation and, in $79 \%$ of pairs that copulated, the male was emitting MS-3. By contrast to the characteristic amplitude increase throughout the MS-2 pulse, no regular amplitude modulation of the MS-3 pulse train was seen.

The dominant frequency of approximately $70 \mathrm{~Hz}$ is lower than that of other species vibratory songs. On the other hand, the spectral width at $20 \mathrm{~dB}$ below the peak amplitude $(20 \pm 4 \mathrm{~Hz}, N=20, n=8)$ lies in the range of other pentatomids.

The MS-1 and/or MS-2 songs were changed into the rivalry song (MRS) (Fig. 5G,H, Table 5) when two (or 
A

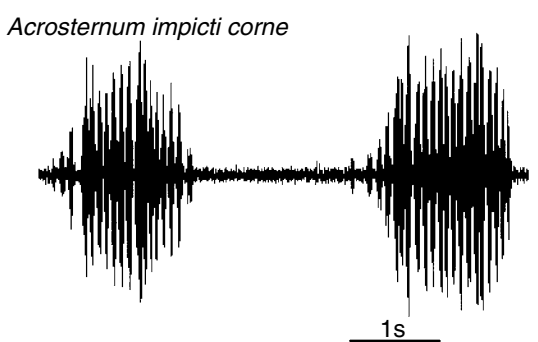

C

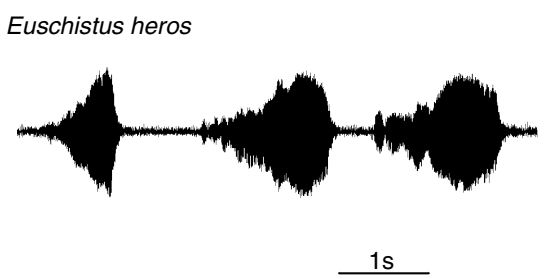

E

Piezodorus guildinii

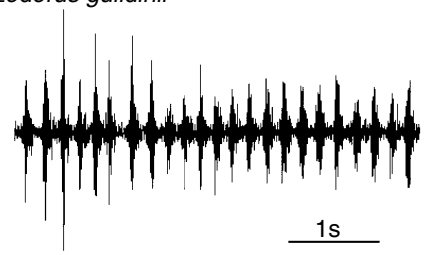

G

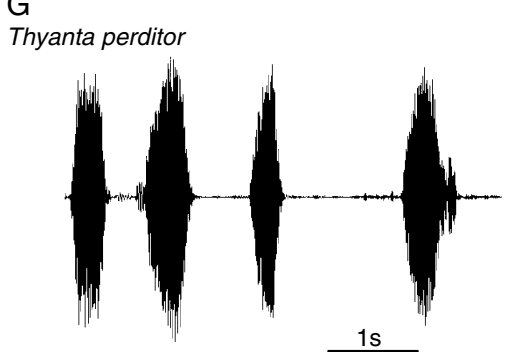

B

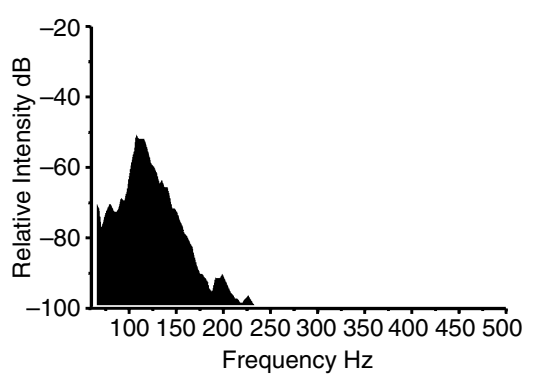

D

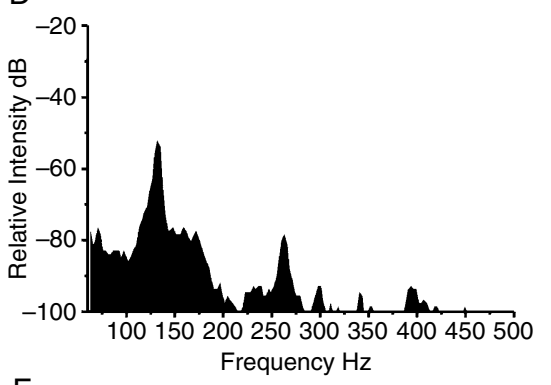

$\mathrm{F}$

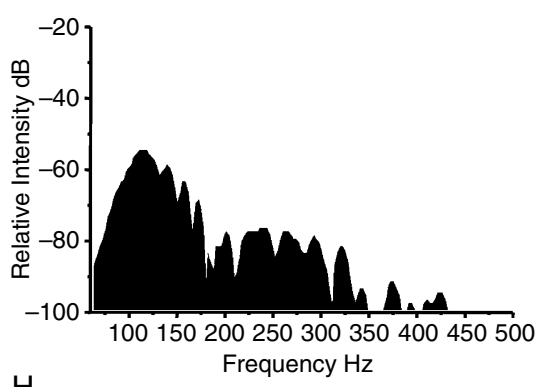

$\mathrm{H}$

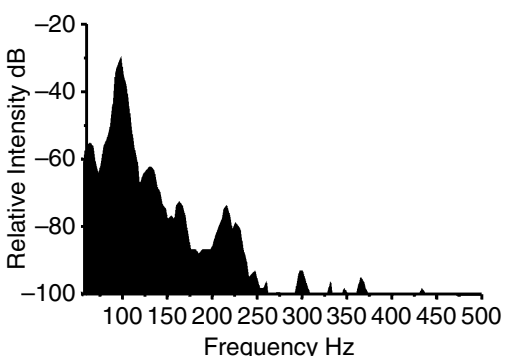

Fig. 3. (A) Oscillogram of Acrosternum impicticorne male song 1 (MS-1) and (B) frequency spectrum of one pulse. (C) Oscillogram of Euschistus heros male song 1 (MS-1) and (D) frequency spectrum of one pulse. (E) Oscillogram of Piezodorus guildinii male song 1 (MS-1) and (F) frequency spectrum of one pulse. (G) Oscillogram of Thyanta perditor male song 1 (MS-1) and (H) frequency spectrum of one pulse. Songs were registered from bugs singing on a loudspeaker membrane. The time scales are marked below each oscillogram. more) males were responding to a single female. Males exchanged pulses of characteristic amplitude modulation in an $\mathrm{a}-\mathrm{b}-\mathrm{a}-\mathrm{b}-\mathrm{a} \ldots$ fashion. Spectra were characterized by $26 \pm 5 \mathrm{~Hz}(N=20, n=2)$ width and by clear and wellestablished first and second harmonic peaks.

\section{Discussion}

The frequency characteristics of four described species vibratory songs fit well into the general scheme of the subfamily Pentatominae (Čokl \& Virant-Doberlet, 2003) and confirm that their spectral properties are tuned for efficient transmission through green plants (Barth, 1998). Narrow band vibrations of frequencies of approximately $100 \mathrm{~Hz}$ are characteristic for songs produced by body vibration (Ewing, 1989) of stink bugs species investigated to date. These signals are transmitted with low attenuation over distances greater than $1 \mathrm{~m}$ through the same plant (Michelsen et al., 1982; Barth, 1998). Such uniform spectral properties are best suited for long-range callings but these signals are also subject to the influence of substrate on their characteristics (Miklas etal., 2001) and thus carry less information about the species. This hypothesis is confirmed by variation of the dominant frequency within and between populations (Čokl et al., 2000b; Miklas et al., 2003) and by changes in the ratio of different spectral peak amplitudes with the distance from the vibration source. By contrast to the 
Table 3. Temporal and spectral properties of males songs 1 (MS-1) of Acrosternum impicticorne, Euschistus heros, Piezodorus guildinii and Thyanta perditor.

\begin{tabular}{|c|c|c|c|c|c|}
\hline Species & & $\begin{array}{l}\text { Duration (ms) } \\
(N / n)\end{array}$ & $\begin{array}{l}\text { Repetition time (ms) } \\
(N / n)\end{array}$ & $\begin{array}{l}\mathrm{P} / \mathrm{PT} \\
(N / n)\end{array}$ & $\begin{array}{l}\text { Dominant frequency }(\mathrm{Hz}) \\
(N / n)\end{array}$ \\
\hline \multirow[t]{2}{*}{ Acrosternum impicticorne } & PT & $\begin{array}{c}943 \pm 5(79 / 4)^{\mathrm{S}} \\
2534 \pm 389(45 / 5)^{\mathrm{L}}\end{array}$ & $\begin{array}{c}8419 \pm 717(47 / 3)^{*} \\
12102 \pm 1287(38 / 3)^{* *}\end{array}$ & $\begin{array}{r}6 \pm 1(79 / 4) \\
12 \pm 3(45 / 5)\end{array}$ & $120 \pm 8(45 / 5)$ \\
\hline & $\mathrm{P}$ & $280 \pm 12(50 / 3)$ & $410 \pm 23(50 / 3)$ & NA & $\begin{array}{r}94 \pm 6(57 / 3) \\
120 \pm 4(67 / 3)\end{array}$ \\
\hline Euschistus heros & PT & $1756 \pm 598(40 / 5)$ & $4378 \pm 1046(36 / 5)$ & ND & $\begin{array}{l}137 \pm 12(173 / 9) \\
173 \pm 9(37 / 5)\end{array}$ \\
\hline Piezodorus guildinii & $\mathrm{P}$ & $24 \pm 5(45 / 3)$ & $30 \pm 8(45 / 3)$ & NA & $117 \pm 10(45 / 3)$ \\
\hline Thyanta perditor & $\begin{array}{l}\text { PT } \\
\text { P }\end{array}$ & $\begin{array}{l}7100 \pm 696(27 / 7) \\
522 \pm 176(127 / 7)\end{array}$ & $\begin{array}{l}\mathrm{ND} \dagger \\
\quad 959 \pm 411(90 / 6)^{*} \\
\quad 903 \pm 89(21 / 1)^{* *}\end{array}$ & $\begin{array}{l}8 \pm 7(27 / 7) \\
\text { NA }\end{array}$ & $\begin{array}{l}\text { ND } \\
122 \pm 15(21 / 1)^{*} \\
110 \pm 11(106 / 6)^{* *}\end{array}$ \\
\hline
\end{tabular}

Means $\pm \mathrm{SD}$ are shown together with the number of tested signals $(N)$ and the number of tested females $(n), N / n$. P-pulses, PT-pulse trains. NA, Not applicable; ND, not determined.

*Singing alone. **Singing in a duet.

${ }^{\mathrm{L}}$ Long pulse.

${ }^{\text {SShort pulse. }}$

$\dagger \mathrm{PT}$ repetition time was not measure because this song is usually alternated or fused with female songs 1 and 2 .

uniformity of spectral characteristics, the temporal structure of stink bug songs expresses a high level of species and sex specificity.

As recorded in previous work, except for $H$. strictus (Pavlovčič \& Čokl, 2001), M. histrionica (Čokl et al., 2004) and P. lituratus (Gogala \& Razpotnik (1974), the first female song functions as a signal to males to approach. FS-1 maybe triggered by male pheromones and are emitted from the same place on a plant for long periods of time with an autonomous and steady rhythmicity of pulses or pulse trains.

Females of $A$. impicticorne, E. heros and $T$. perditor emitted the calling song, which fits well into the described scheme. The main differences between them and other species (Čokl \& Virant-Doberlet, 2003) are the duration and repetition rate of pulses and/or pulse trains. Although the female calling song of $A$. impicticorne and E. heros shows a similarity of their temporal pattern with $N$. viridula and A. hilare (Čokl etal., 2001), FS-1 of $T$. perditor differs from the rest by the long pulse trains of several seconds duration repeated at a low rate.

The absence of a calling function of the female songs of small pentatomine species such as H. strictus (Pavlovčič \& Čokl, 2001) and M. histrionica (Čokl et al., 2004) may be explained by the short distance between the legs $(<1 \mathrm{~cm})$, which may prevent vibrational directionality (Čokl et al., 1999). According to the physical characteristics of transmission of vibratory signals on plants, it was proposed that a minimal distance of $1 \mathrm{~cm}$ is required between receptors to resolve directionality (Čokl \& Virant-Doberlet, 2003). In this fashion, the absence of female songs in P. lituratus (Gogala \& Razpotnik, 1974), and the irregularity of its emission in $P$. guildinii, indicates that the song repertoire of the genus Piezodorus deserves attention as being different from those of other Pentatominae.
The stereotypical response of a male to female calling is movement towards her and the emission of vibratory signals MS-1 and MS-2, and, in the majority of investigated stink bug species, this develops into the courtship song (MS-3), which is the main male song used in dueting with a female. Courtship songs are composed of complex pulse trains, the duration and repetition rate of which are determined by the rhythmicity of female calling song signals (Miklas et al., 2002).

High species specificity of the male courtship song may be encoded by different combinations of the song's components, as well as in amplitude modulation. The complex structure of the signal may function as the code for species recognition at short distances. However, when the signals are transmitted over long distances (e.g. during transmission through a plant), the signal's pattern may vary due to reflections and standing wave conditions, which may occur in rod structures, such as stems and stalks (Michelsen et al., 1982). Signal distortion occurs due to the mechanical heterogeneity of plants, whereas interference and superimposing of waves occur as a consequence of reflections from the ends of the plant or parts of it (Barth, 1998), and this could interfere with the recognition of these signals at long distance (Č́okl \& Virant-Doberlet, 2003)

In general, the calling songs of stink bugs have vibratory signals with narrow bands that gives rise to well-expressed higher harmonics. These signals propagate over long distances with minimal variation through the plants. In early experiments in $N$. viridula and $N$. antennata, it was demonstrated that the repetition rate of female calling song signals remains constant for a long time when reinforced by male responding (Čokl \& Bogataj, 1982).

Recently, in $N$. viridula, it was demonstrated that female/ male dueting is influenced by the species-specific pheromone 
A

Acrosternum impicticorne

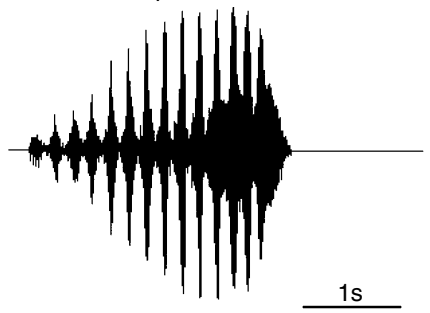

C

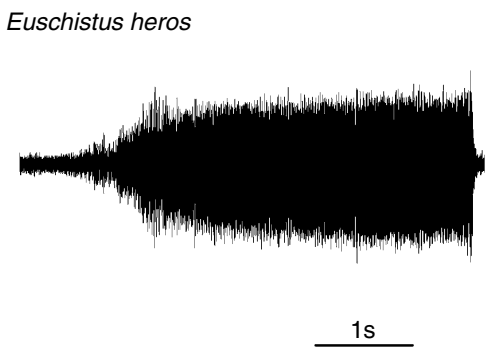

E

Thyanta perditor

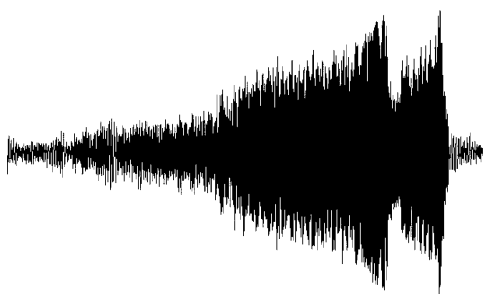

1s
B

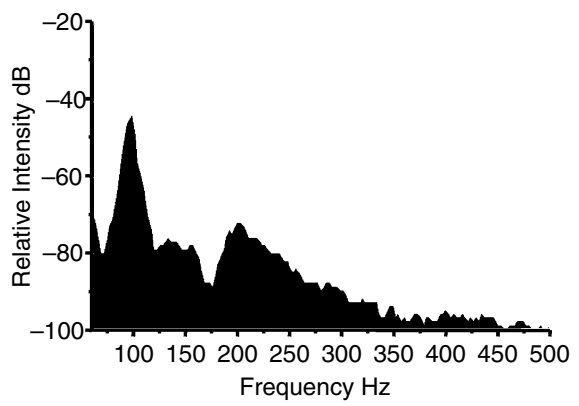

D

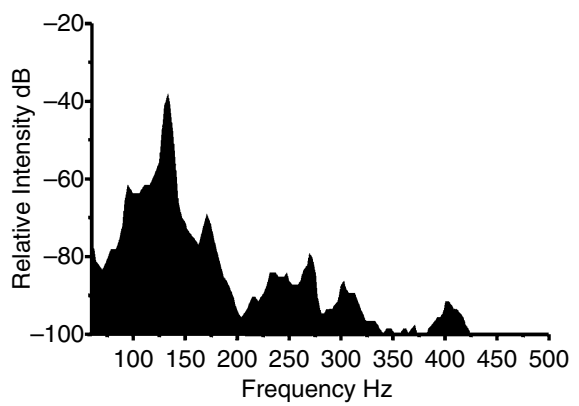

F

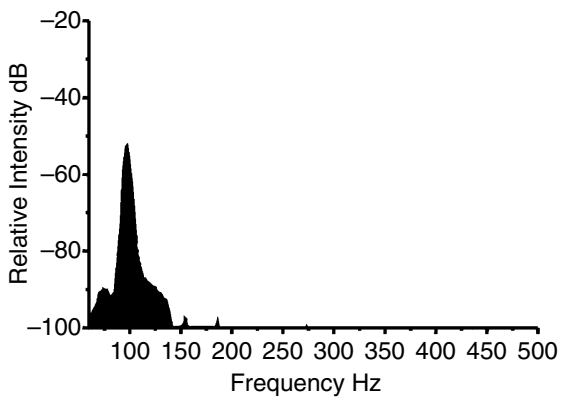

Fig. 4. (A) Oscillogram of Acrosternum impicticorne male song 2 (MS-2) and (B) frequency spectrum of one pulse. (C) Oscillogram of Euschistus heros male song 2 (MS-2) and (D) frequency spectrum of one pulse. (E) Oscillogram of Thyanta perditor male song 2 (MS-2) and (F) frequency spectrum of one pulse and The songs were registered from bugs singing on a loudspeaker membrane. The time scales are marked below each oscillogram.

Table 4. Temporal and spectral properties of male song 2 (MS-2) of Acrosternum impicticorne, Euschistus heros, Piezodorus guildinii and Thyanta perditor.

\begin{tabular}{|c|c|c|c|c|c|}
\hline Species & & $\begin{array}{l}\text { Duration (ms) } \\
(N / n)\end{array}$ & $\begin{array}{l}\text { Repetition time (ms) } \\
(N / n)\end{array}$ & $\begin{array}{l}\mathrm{P} / \mathrm{PT} \\
(N / n)\end{array}$ & $\begin{array}{l}\text { Dominant frequency }(\mathrm{Hz}) \\
(N / n)\end{array}$ \\
\hline Acrosternum impicticorne & PT & $\begin{aligned} 938 & \pm 54(34 / 3) \\
2479 & \pm 331(114 / 5)\end{aligned}$ & $3598 \pm 1703(87 / 7)$ & $\begin{aligned} 6 & \pm 1(114 / 5) \\
10 & \pm 4(86 / 7)\end{aligned}$ & $\begin{aligned} 130 & \pm 2(65 / 5)^{*} \\
92 & \pm 2(43 / 5)^{* *}\end{aligned}$ \\
\hline & $\mathrm{P}$ & $\begin{array}{r}136 \pm 5(336 / 2) \\
82 \pm 2(271 / 4)\end{array}$ & $197 \pm 23(632 / 8)$ & NA & NA \\
\hline Euschistus heros & PT & $4407 \pm 582(20 / 3)$ & ND & ND & $\begin{array}{l}136 \pm 13(20 / 3) \\
172 \pm 9(20 / 3)\end{array}$ \\
\hline Thyanta perditor & $\mathrm{P}$ & $\begin{array}{l}3390 \pm 990(40 / 7)^{*} \\
4490 \pm 1290(8 / 1)^{* *}\end{array}$ & NA & NA & $109 \pm 12(40 / 8)$ \\
\hline
\end{tabular}

Means \pm SD are shown together with the number of tested signals $(N)$ and the number of tested females $(n), N / n$. P-pulses, PT-pulse trains. NA, Not applicable; ND, not determined.

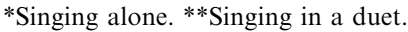


A

Acrosternum impicticorne

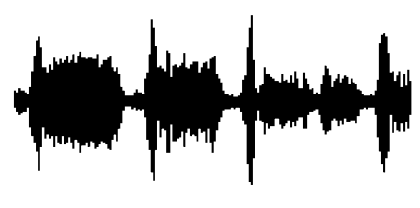

$1 \mathrm{~s}$

C

Euschistus heros

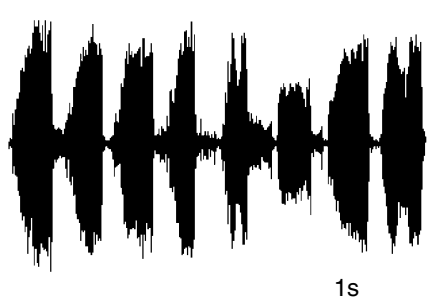

$\mathrm{E}$

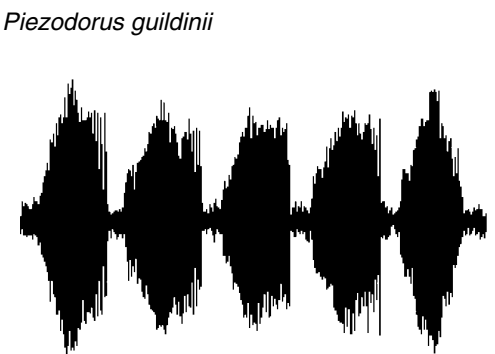

1s

G

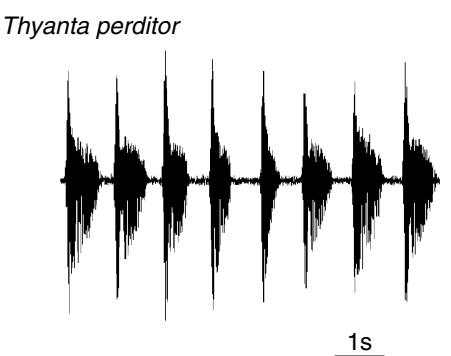

B

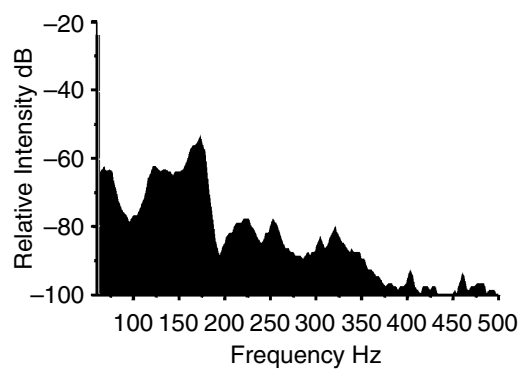

D

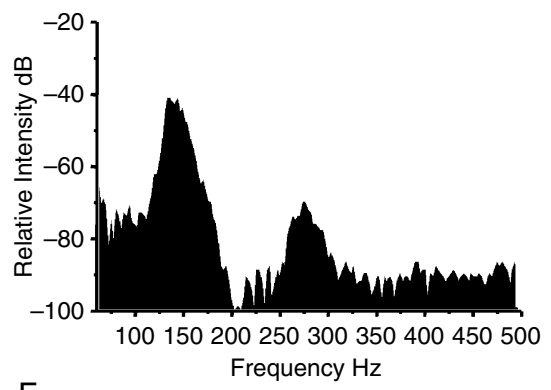

F

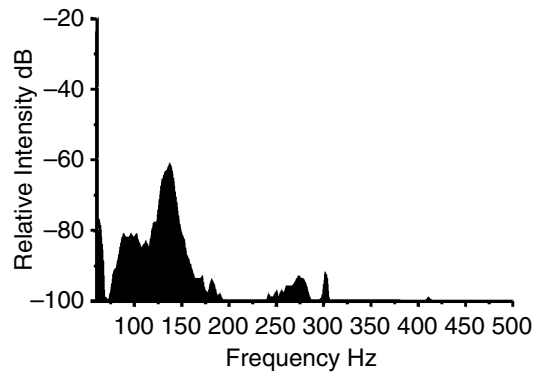

$\mathrm{H}$

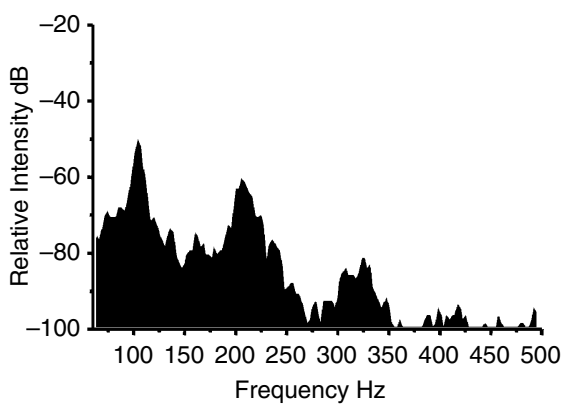

Fig.5. (A) Oscillogram of Acrosternum impicticorne male rivalry song (MRS).

(B) frequency spectrum of one pulse. (C) Oscillogram of Euschistus heros male rivalry song (MRS) and (D) frequency spectrum of one pulse. (E) Oscillogram of Piezodorus guildinii male rivalry song (MRS) and (F) frequency spectrum of one pulse. (G) Oscillogram of Thyanta perditor male rivalry song (MRS) and (H) frequency spectrum of one pulse. Songs were registered from bugs singing on a loudspeaker membrane. The time scales marked below each oscillogram. produced by the male (Miklas et al., 2003). On the other hand, Miklas etal. (2003) demonstrated that male bugs modulate pheromone emission in response to vibratory signals of conspecific females. This brings a new dimension to investigations of problems of multimodality and the species specificity of different signals because pheromones and/or other male-emitted chemical signals may isolate species both in the field and on the plant, reducing the need for vibrational communication. The area of bimodal communication in stink bugs and other insects requires further study.

The function of the first emitted male song (MS-1) is not clear because, in most species, it represents a transitional 
Table 5. Temporal and spectral properties of male rivalry song (MRS) of Acrosternum impicticorne, Euschistus heros, Piezodorus guildinii and Thyanta perditor.

\begin{tabular}{|c|c|c|c|c|}
\hline Species & & $\begin{array}{l}\text { Duration (ms) } \\
(N / n)\end{array}$ & $\begin{array}{l}\text { Repetition time (ms) } \\
(N / n)\end{array}$ & $\begin{array}{l}\text { Dominant frequency }(\mathrm{Hz}) \\
(N / n)\end{array}$ \\
\hline Acrosternum impicticorne & $\mathrm{P}$ & $1330 \pm 400(101 / 3)$ & $1493 \pm 490(101 / 3)$ & $107 \pm 2(101 / 3)$ \\
\hline Euschistus heros & $\mathrm{P}$ & $984 \pm 275(40 / 1)$ & $1151 \pm 298(40 / 1)$ & $149 \pm 9(40 / 1)$ \\
\hline Piezodorus guildinii & $\mathrm{P}$ & $980 \pm 50(33 / 3)$ & $1640 \pm 80(33 / 3)$ & $135 \pm 8(33 / 3)$ \\
\hline Thyanta perditor & $\mathrm{P}$ & $680 \pm 50(53 / 4)$ & $1250 \pm 360(53 / 4)$ & $102 \pm 6(53 / 4)$ \\
\hline
\end{tabular}

Means \pm SD are shown together with the number of tested signals $(N)$ and the number of tested females $(n), N / n$. P-pulses, PT-pulse trains.

form to the courtship or rivalry song and, in some species, such as $P$. guildinii and $A$. hilare, it remains as the only response to female singing. This song is characteristically composed of single pulses in P. guildinii, E. conspersus, $N$. viridula, $T$. pallidovirens, $T$. custator accerra, $P$. prasina and $P$. virridissima, or pulses grouped into trains in $T$. perditor, H. strictus and E. heros (Kon etal., 1988; Čokl etal., 2000a, Čokl etal., 2001, McBrien etal., 2002; McBrien \& Millar 2003). Except for E. heros, MS-1 pulses are shorter than $500 \mathrm{~ms}$ and, during transition to the courtship song, their repetition rate increases until they fuse into pulse trains of different temporal structures. There are no data to confirm any modulation of female behaviour connected with the emission of the first male song, and the song's calling or identification function is dubious because of its unstable emission and temporal pattern.

During male courting, antennation and butting females appears to stimulate the change of the calling song into another song (FS-2), the function of which could be compared with that of the male courtship song. Readily repeated pulses or pulse trains are replaced by long units of irregular repetition rate, as described for $N$. viridula (Čokl et al., 2001), T. pallidovirens and T. custator accerra (McBrien et al., 2002), as well as for E. heros and A. impicticorne in the present study. In H. strictus, pulses organized into pulse trains become longer (Pavlovčič \& Čokl, 2001), whereas the opposite process could be demonstrated in E. conspersus (McBrien \& Millar, 2003), in which long pulses of the calling song are replaced by short ones in the second female song. Different female signals emitted in the absence or presence of a male, as recorded in $P$. guidinii and $T$. perditor, could be transitional forms of the same song. The second female song was identified only recently and more investigations are needed to confirm its role in closerange communication between mates. In all four stink bug species from soybeans, the male rivalry song is recorded
Euschistus heros

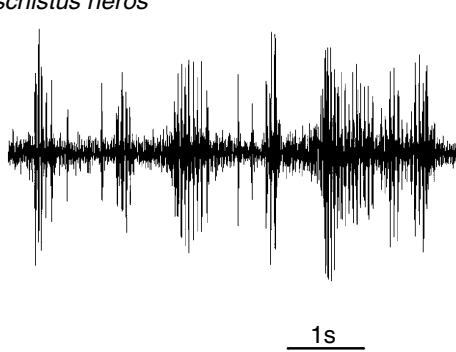

C

Thyanta perditor

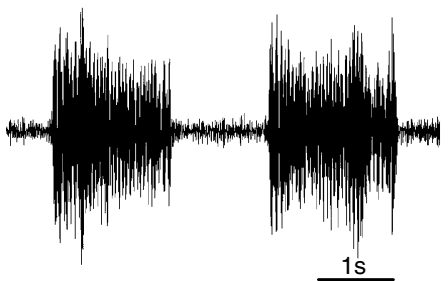

B

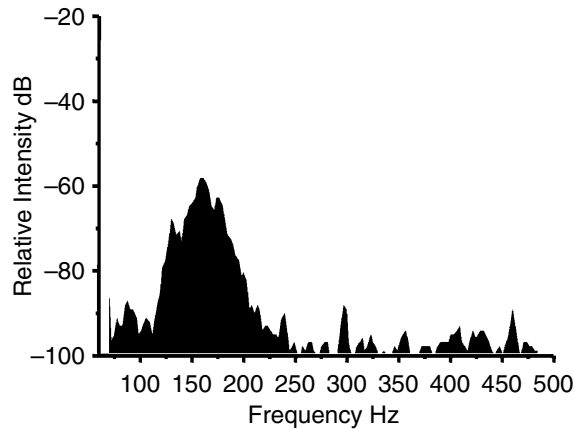

D

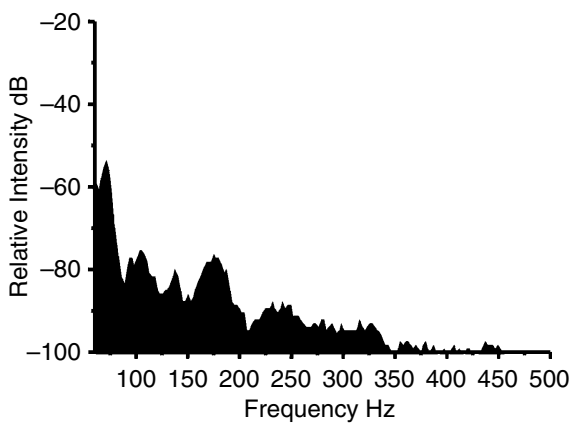

Fig. 6. (A) Oscillogram of Euschistus heros male song 3 (MS-3) and (B) frequency spectrum of one pulse. (C) Oscillogram of Thyanta perditor male song 3 (MS-3) and (D) frequency spectrum of one pulse. Songs were registered from bugs singing on a loudspeaker membrane. The time scales are marked below each oscillogram. 
Table 6. Temporal and spectral properties of male song 3 (MS-3) of Euschistus heros, and Thyanta perditor.

\begin{tabular}{|c|c|c|c|c|}
\hline Species & & $\begin{array}{l}\text { Duration (ms) } \\
(N / n)\end{array}$ & $\begin{array}{l}\text { Repetition time (ms) } \\
(N / n)\end{array}$ & $\begin{array}{l}\text { Dominant frequency }(\mathrm{Hz}) \\
(N / n)\end{array}$ \\
\hline Euschistus heros & $\mathrm{P}$ & $54 \pm 9(58 / 2)$ & $81 \pm 12(53 / 2)$ & $175 \pm 5(25 / 2)$ \\
\hline Thyanta perditor & $\mathrm{PT}$ & $2110 \pm 460(138 / 12)$ & $5290 \pm 1380(138 / 12)$ & $70 \pm 7(138 / 12)$ \\
\hline
\end{tabular}

Means \pm SD are shown together with the number of tested signals $(N)$ and the number of tested females $(n), N / n$. P-pulses, PT-pulse trains.

with the typical characteristics described for $N$. viridula (Čokl et al., 2001).

Although it can be concluded that, except for $P$. guildinii, the songs of all of the species investigated fit into the general pattern of vibratory communication in Pentatominae, several questions remain unanswered. The results, which were obtained in an artificial system, need to be verified in subsequent studies using bugs on plants. Moreover, studies on the functional value of statistically determined differences between songs are lacking, and there are no data regarding the role of different host plants on the quality of vibratory signals exchanged during communication at different distances. Bimodal communication with olfactory and vibratory signals requires detailed studies on the nature of chemical signals involved and, finally, signals of other modalities, such as touch, vision and even low frequency near-field sound emitted by mates immediately before copulation.

\section{Acknowledgements}

The authors are grateful to Hélio Moreira dos Santos, Diva Tiburcio, Rodrigo S. F. Passos and Danielle Moura Cordeiro for help with field collecting, laboratory rearing and recording data for the insects used in this study. This work received financial support from CNPq and EmbrapaRecursos Genéticos e Biotecnologia. The study was supported by the EMBRAPA grant to Dr Andrej Čokl and Program P1-0255 (Slovenian Ministry for Education, Science and Sports).

\section{References}

Barth, F.G. (1998) The vibrational sense of spiders. Comparative Hearing in Insects (ed. by R. R. Hoy, A. N. Popper and R. R. Fay), pp. 228-278. Springer-Verlag, New York, New York.

Borges, M., Jepson, P.C. \& Howse, P.E. (1987) Long-range mate location and close-range courtship behaviour of the green stink bug, Nezara viridula and its mediation by sex pheromones. Entomologia Experimentalis et Applicata, 44, 205-212.

Brennan, B.M., Chang, F. \& Mitchell, W.C. (1977) Physiological effects on sex pheromone communication in the southern green stink bug, Nezara viridula. Environmental Entomology, 6, 169-173.

Broughton, W.B. (1963) Method in bio-acoustic terminology. Acoustic Behaviour of Animals (ed. by R. G. Busnel), pp. 3-24. Elsevier, The Netherlands.
Čokl, A. \& Bogataj, E. (1982) Factors affecting vibrational communication in Nezara viridula L. (Heteroptera, Pentatomidae). Bioloski Vestnik (Ljubljana), 30, 1-20.

Čokl, A. \& Virant-Doberlet, M. (2003) Communication with substrate-borne signals in small plant-dwelling insects. Annual Review of Entomology, 48, 29-50.

Čokl, A., Gogala, M. \& Blaževiè, A. (1978) Principles of sound recognition in three pentatomide bug species (Heteroptera). Bioloski Vestnik (Ljubljana), 26, 81-94.

Čokl, A., Virant-Doberlet, M. \& McDowell, A. (1999) Vibrational directionality in the southern green stink bug, Nezara viridula (L.), is mediated by female songs. Animal Behaviour, 58, 1277-1283.

Čokl, A., Virant-Doberlet, M. \& Stritih, N. (2000a) Temporal and spectral properties of the songs of the southern green stink bug Nezara viridula (L.) from Slovenia. Pflügers Archive - European Journal of Physiology, 439, R168-R170.

Čokl, A., Virant-Doberlet, M. \& Stritih, N. (2000b) The structure and function of songs emitted by the southern green stink bugs from Brazil, Florida, Italy and Slovenia. Physiological Entomology, 25, 196-205.

Čokl, A., McBrien, H.L. \& Millar, J.G. (2001) Comparison of substrate-borne vibrational signals of two stink bug species, Acrosternum hilare and Nezara viridula (Heteroptera, Pentatomidae). Annals of the Entomological Society of America, 94, 471-479.

Čokl, A., Prešern, J., Virant-Doberlet, M. et al. (2004) Vibratory signals of the harlequin bug and their transmission through plants. Physiological Entomology, 29, 372-380.

Costa, M.L.M., Borges, M. \& Vilela, E.F. (1998) Biologia reprodutiva de Euschistus heros (F.) (Heteroptera: Pentatomidae). Anais da Sociedade Entomologica do Brasil, 27, 559-568.

Ewing, A.W. (1989) Mechanisms of sound production. Arthropod Bioacoustics, Neurobiology and Behavior (ed. by A. W. Ewing), pp. 16-57. Edinburgh University Press, U.K.

Gogala, M. \& Razpotnik, R. (1974) An oscillographic-sonagraphic method in bioacoustical research. Bioloski Vestnik (Ljubljana), 22, 209-216.

Kiritani, K., Hokyo, N. \& Yukawa, J. (1963) Coexistences of the two related stink bugs Nezara viridula and $N$. antennata under natural conditions. Research of Population Ecology, 5, 11-22.

Kon, M., Oe, A., Numata, H. \& Hidaka, T. (1988) Comparison of the mating behaviour between two sympatric species, Nezara antennata and $N$. viridula (Heteroptera: Pentatomidae), with special reference to sound emission. Journal of Ethology, $\mathbf{6}$, 91-98.

McBrien, H.L. \& Millar, J.G. (1999) Phytophagous bugs. Pheromones of Non-Lepidopteran Insects Associated with Agricultural Plants (ed. by J. Hardie and A. K. Minks), pp. 277-304. CAB, U.K.

McBrien, H.L. \& Millar, J.G. (2003) Substrate-borne vibrational signals of the consperse stink bug (Hemiptera: Pentatomidae). Canadian Entomologist, 135, 555-567. 
McBrien, H.L., Čokl, A. \& Millar, J.G. (2002) Comparison of substrate-borne vibrational signals of two congeneric stink bug species, Thyanta pallidovirens and T. custator accerra. Journal of Insect Behavior, 15, 715-737.

Michelsen, A., Fink, F., Gogala, M. \& Traue, D. (1982) Plants as transmission channels for insect vibrational songs. Behavioral Ecology Sociobiology, 11, 269-281.

Miklas, N., Stritih, N., Čokl, A. et al. (2001) The influence of substrate on male responsiveness to the female calling song in Nezara viridula. Journal of Insect Behavior, 14, 313-332.

Miklas, N., Čokl, A., Renou, M. \& Virant-Doberlet, M. (2002) Variability of vibratory signals and mate choice selectivity in the southern green stink bug. Behavioural Processes, 61, 131-142.
Miklas, N., Lasnier, T. \& Renou, M. (2003) Male bugs modulate pheromone emission in response to vibratory signals from conspecifics. Journal of Chemical Ecology, 29, 561-574.

Panizzi, A.R., McPherson, J.E., James, D.G. et al. (2000) Stink Bugs (Pentatomidae). Heteroptera of Economic Importance (ed. by C. W. Schaefer and A. R. Panizzi), pp. 421-474. CRC Press, Boca Raton, Florida.

Pavlovčič, P. \& Čokl, A. (2001) Songs of Holcostethus strictus (Fabricius): a different repertoire among landbugs (Heteroptera: Pentatomidae). Behavioural Processes, 53, 65-73.

Accepted 26 November 2004 